\title{
Predicting difficult-to-treat chronic rhinosinusitis by noninvasive biological markers*
}

\section{Cui-Lian Guo\#, Bo Liao\#, Jin-Xin Liu, Li Pan, Zheng Liu}

Department of Otolaryngology-Head and Neck Surgery, Tongji Hospital, Tongji Medical College, Huazhong University of Science and Technology, Wuhan, PR China
Rhinology 59: 1, 81 - 90, 2021

https://doi.org/10.4193/Rhin20.103

*Received for publication:

March 23, 2020

Accepted: July 25, 2020

" contributed equally to this work

\section{Abstract}

Background: Previous studies have been limited to the utility of clinical features and invasive nasal mucosal biomarkers in the prediction of chronic rhinosinusitis (CRS) outcomes. This study aimed to identify noninvasive biomarkers associated with difficultto-treat CRS, enabling physicians to subgroup patients into risk groups for poor outcome before surgery.

Methods: Three hundred and nine CRS patients undergoing endoscopic sinus surgery were finally enrolled. Patients treated with oral or intranasal glucocorticoids within 3 months or 1 month before surgery, respectively, were excluded. Baseline clinical characteristics, nasal secretions and peripheral blood samples were collected before surgery. The protein levels of 39 biological markers were detected by the Bio-Plex suspension chip method. Classification and regression tree analysis was applied to establish prediction model for difficult-to-treat CRS determined one year after surgery. A random forest algorithm was used to confirm the discriminating factors that formed the classification tree.

Results: In the cohort with nasal secretion sample $(n=189), 21 \%$ of CRS patients were diagnosed as difficult-to-treat after 1 year of follow-up. Nasal secretion CCL17 level, hyposmia score, allergic rhinitis comorbidity, and nasal secretion MIP-1 $\beta$ level were found important predictors of difficult-to-treat CRS. A classification tree separated patients into 5 subgroups leading to an overall predictive accuracy of $94 \%$. However, none of the plasma biological markers were associated with difficult-to-treat CRS in the cohort with blood sample $(n=128)$.

Conclusions: Patients with difficult-to-treat-CRS were characterized by higher nasal secretion levels of CCL17 and MIP-1 $\beta$, severe hyposmia and concomitant allergic rhinitis. The classification tree could be useful to identify patients with high risk of poor outcome prior to surgery and offer more personalized interventions. However, since only patients without preoperative steroid treatments were included in this study, the generalization of our predictive model in other patient populations should be considered with caution.

Key words: chronic rhinosinusitis; difficult-to-treat; nasal secretions; noninvasive; classification and regression tree

\section{Introduction}

Chronic rhinosinusitis (CRS) characterised by complex and highly heterogeneous chronic sinonasal inflammation affects $5 \%$ to $12 \%$ of the general population ${ }^{(1)}$. A large proportion of patients do not respond well to appropriate medical therapy and are offered endoscopic sinus surgery (ESS), followed by po- stoperative medical treatment maintenance ${ }^{(1)}$. It is increasingly recognized that CRS comprises several variants with distinct clinical presentations and multiple biological endotypes, leading to a diverse disease prognosis ${ }^{(2,3)}$. Thus, the typical "one size fits all" treatment paradigm may not achieve the best outcome for all CRS endotypes. In our previous study, around $29 \%$ of CRS 
patients were diagnosed as difficult-to-treat despite adequate treatment ${ }^{(2)}$. It is challenging for physicians to predict difficultto-treat CRS in patients with complicated endotypes and inflammatory status, while the analysis of potential risk factors related to prognosis is considered helpful due to the high morbidity and difficult-to-treat rates of CRS.

Numerous attempts have focused on identifying the risk factors associated with CRS poor outcome. Clinical factors, such as allergic rhinitis, asthma, high blood eosinophil ratio and high preoperative computed tomography (CT) scores were reported to be associated with an increased risk of recurrence or refractoriness in CRS ${ }^{(4,5)}$. Tissue-derived biomarkers, such as tissue eosinophilia, interleukin (IL)-5, IL-25, immunoglobulin (Ig)E and Charcot-Leyden crystals, were also assigned to predict CRS outcomes ${ }^{(6-8)}$. Our prospective study also demonstrated that combined clinical and tissue molecular markers could predict difficult-to-treat CRS with valuable efficiency ${ }^{(9)}$. However, compared to the collection of nasal secretions and peripheral blood samples, the tissue-based approach is inherently invasive and time-consuming, and the site-specific protein levels from the sinonasal cavity are variable ${ }^{(10)}$. In addition, most of the previous publications were limited by their retrospective designs and the definitions of disease outcomes were inconsistent among studies. Biomarkers from noninvasive samples, including blood, nasal mucus and brushing have been found to be linked to the disease severity or response to glucocorticoid treatment in patients with CRS ${ }^{(11-13)}$. Chowdhury et al. investigated 17 mucus cytokines from 62 CRS patients to predict 22-item Sino-Nasal Outcome Test results after ESS ${ }^{(12)}$. However, the small sample size limited the statistical power of the study and no detailed predictive model was provided for clinical use ${ }^{(12)}$. Literature comprehensively exploring the utility of nasal secretion and peripheral blood biomarkers in predicting CRS outcomes remains scarce.

Previously, the multivariate logistic regression analysis has been commonly applied to identify predictors associated with poor outcome of CRS ${ }^{(9)}$. One limitation of those models is the lengthy calculations since all variables within the models are used simultaneously, making it difficult to be implemented in clinical practice ${ }^{(14)}$. Classification and regression tree (CART) analysis is a machine-learning method which recursively partitions a sample into subgroups as homogenous as possible based on the predictive importance of variables ${ }^{(15)}$. It generates a "classification tree" with a flow-chart-like structure which can be easily implemented and interpreted without requiring numeric calculations ${ }^{(14)}$. Our study aimed to evaluate the most influential factors for treatment outcomes of CRS patients undergoing ESS. Noninvasive or minimally invasive biomarkers from nasal secretions or peripheral blood samples potentially associated with difficultto-treat CRS were comprehensively analysed. A prediction model consisting of four clinical and mucus factors was constructed by CART analysis. It yielded a better predictive accuracy than the multivariate logistic regression model, which was composed of tissue-based biomarkers ${ }^{(9)}$, and could assist physicians in identifying patients with high risk of poor outcome and providing early and personalised intervention.

\section{Materials and methods}

Subjects

CRS was diagnosed according to the European Position Paper on Rhinosinusitis and Nasal Polyps (EPOS) (1). Patients with ongoing symptoms despite appropriate medical management and scheduled for ESS were eligible for the study. Exclusion criteria included the followings: 1 ) patients under 18 years old, 2) patients with an acute upper respiratory tract infection or acute asthma episode within 4 weeks before surgery, 3) patients treated with oral or intranasal glucocorticoids within 3 months or 1 month before surgery, respectively, and 4) patients with fungal rhinosinusitis, antrochoanal polyps, systemic vasculitis, primary ciliary dyskinesia, cystic fibrosis, inverted papilloma or immune deficiency. In China, after failure of medical treatments and being in the waiting list for surgery, a lot of patients may not adhere well to medications including steroids before surgery. After being hospitalized, patients receive operations in 2-3 days after completion of general pre-surgery preparation. Thus, we have the opportunity to enroll patients without presurgical steroid treatment to avoid the interference of steroid treatment on cytokine levels. In the present study, 11 patients were excluded due to the steroid-exclusion criteria and no nasal secretion sample or plasma sample was collected from these patients. Finally, a total of 309 Chinese CRS patients were enrolled from January 2015 to December 2017, with 229 patients providing nasal secretion samples and 146 patients providing peripheral blood samples (66 patients with both samples). After excluding those without adequate samples or lost to follow-up after ESS, 189 and 128 patients were finally analysed in nasal secretion sample group and blood sample group, respectively (Figure 1). There were 79 patients also included in our previous study of predicting CRS outcome with tissue biomarkers ${ }^{(9)}$, with 60 patients providing nasal secretion samples, 38 patients providing peripheral blood samples, and 19 patients providing both samples.

This study was approved by the Ethics Committee of Tongji Hospital of Huazhong University of Science and Technology, Wuhan, China, and informed consent was obtained from every subject.

Baseline assessment and sample collection before surgery Before surgery, demographic and clinical information were collected. Atopic status was determined through a skin prick test with a standard panel of common inhalant allergens (MacroUnion Pharmaceutical, Beijing, China) or by detecting serum allergen-specific IgE antibodies with ImmunoCAP (Phadia, Uppsala, Sweden) ${ }^{(16,17)}$. The diagnosis of allergic rhinitis was 
based on the concordance between a typical history of allergic symptoms and the atopy test results ${ }^{(18)}$. The diagnosis of asthma was based on guidelines recommended by the Global Initiative for Asthma (GINA) ${ }^{(19)}$. CRS symptoms, including nasal obstruction, rhinorrhoea, facial pain/pressure, headache and loss of smell, were scored on a visual analog scale (VAS) from zero (no symptom) to 10 (maximum) and the overall burden caused by CRS was also recorded as previously reported ${ }^{\text {(2). }}$. CT scans and nasal endoscopic findings were recorded by the Lund-Mackay and Lanza-Kennedy scoring system, respectively ${ }^{(20)}$. The complete blood cell count was performed by automated analysis within 2-3 days before surgery ${ }^{(21)}$.

Before surgery, peripheral blood samples or nasal secretion samples were collected according to patients' willingness and the sample collection process was standardized for all patients. For peripheral blood sample, it was collected on empty stomach at early morning in two or three days before surgery in the ward. Peripheral blood samples were collected with EDTA tubes and centrifuged for 10 minutes at $3000 \mathrm{~g}$. The supernatant plasma was collected and frozen at $-80^{\circ} \mathrm{C}$ until analysis. Nasal secretion samples were collected under general anaesthesia and just before surgical procedure ${ }^{(22,23)}$. Briefly, sponges were inserted into the bilateral nasal cavities for 5 minutes and put in an Eppendorf tube containing $2 \mathrm{~mL}$ of sterile $0.9 \% \mathrm{NaCl}$ for 30 minutes on ice to mobilise the nasal secretions. Sponges were transferred into a syringe and the liquid was squeezed out into an Eppendorf tube. Then Eppendorf tube was centrifuged at $1500 \mathrm{~g}$ for $10 \mathrm{mi}-$ nutes and the supernatants were collected and frozen at $-80^{\circ} \mathrm{C}$ until analysis.

Follow-up, medical treatment and outcome assessment All operations were performed by fellowship-trained rhinologists in accordance with the commonly accepted functional ESS principles. Patients were followed up at 1, 3, 6, and 12 months after surgery, and additional visits to the physician were allowed. The outcome was assessed at 12-month post-ESS. During the follow-up period, patients were routinely instructed to use an intranasal spray of corticosteroid and saline irrigation twice a day. Patients with uncontrolled symptoms (VAS >5) were given 1-2 weeks of broad-spectrum antibiotics and/or systemic corticosteroids for 20 days as previously described ${ }^{2,24)}$. Patients with asthma were treated with inhaled corticosteroid and/or a long-acting beta 2 agonist based on the GINA recommendations ${ }^{(19)}$. At each follow-up visit, the symptoms (nasal blockage, rhinorrhoea/postnasal drip, facial pain/ headache, smell and sleep disturbance/fatigue) in the last month, the nasal endoscopy appearance, and the need of systemic medication were recorded. Individual symptom with VAS > 5 was considered as present and bothersome ${ }^{(24)}$. According to the scheme in EPOS, CRS patients were defined as controlled, partly controlled and uncontrolled (Table E1). Controlled CRS is defined as no bothersome symptoms, with healthy or almost healthy mucosa and no need for systemic medicine to control disease. Partly controlled patients experience less than two of the following items: persistent nasal blockage, mucopurulent rhinorrhoea/ postnasal drip, facial pain, impaired smell, sleep disturbance/ fatigue, diseased mucosa, and the need of a course of antibiotics or systemic corticosteroids in the last three months. Uncontrolled CRS is defined as having three or more features of partly controlled CRS and need of long-term antibiotics or systemic corticosteroids in the last month (Table E1) ${ }^{(1,4)}$. Patients who did not reach an acceptable level of control (controlled or partially controlled) despite adequate surgery, intranasal corticosteroid treatment, and up to 2 short courses of antibiotics or systemic corticosteroids in the last year were considered to have difficultto-treat CRS ${ }^{(1,9)}$.

\section{Measurement of inflammatory markers}

The protein levels of 39 biological markers were detected using the Bio-Plex suspension chip method (Bio-Rad, Hercules, Calif, USA) according to the manufacturer's instructions ${ }^{(25)}$. The lower detection limits of biological markers were summarized in Table E2 in the Online Repository. Cytokine values below the lower detection limits were replaced by the values representing $1 / 10$ of the detection limit ${ }^{(2)}$. Since the protein concentrations of IL-33, G-CSF, GM-CSF and IFN- $\gamma$ were below the lower detection limits in more than three quarters of plasma samples, these biomarkers were excluded from analysis in the cohort with blood sample. The concentrations of nasal secretion biomarkers were normalised to total protein concentrations ${ }^{(2)}$.

\section{Statistical analysis}

For continuous variables, a Kolmogorov-Smirnov test was used to test the data distribution. Since continuous variables did not follow normal distribution, the Mann-Whitney U 2-tailed test was used for between-group comparisons. For dichotomous variables, a chi-squared test or Fisher's exact test was applied to compare the differences between groups. $\mathrm{P}<0.05$ was considered statistically significant. Statistical analysis was performed using an IBM SPSS 22.0 package (SPSS Inc, Chicago, IL, USA). To identify the most predictive variables, CART analysis was conducted using the classification tree algorithms ${ }^{(15)}$. The variables significantly different between the two groups were included in the CART analysis (for clinical factors: $\mathrm{P}<0.01$; for nasal secretion biomarkers: $\mathrm{P}<0.05)$.The CART analysis allowed to select variables based on the order of predictive powers and the most important variable were included first as the root of the classification tree; the searching process will end when additional variables cannot contribute enough to the predictive model. Random forest (RF) analysis was also conducted to support the analysis result of the CART analysis. RF created a collection of independent decision trees and each tree was built based 


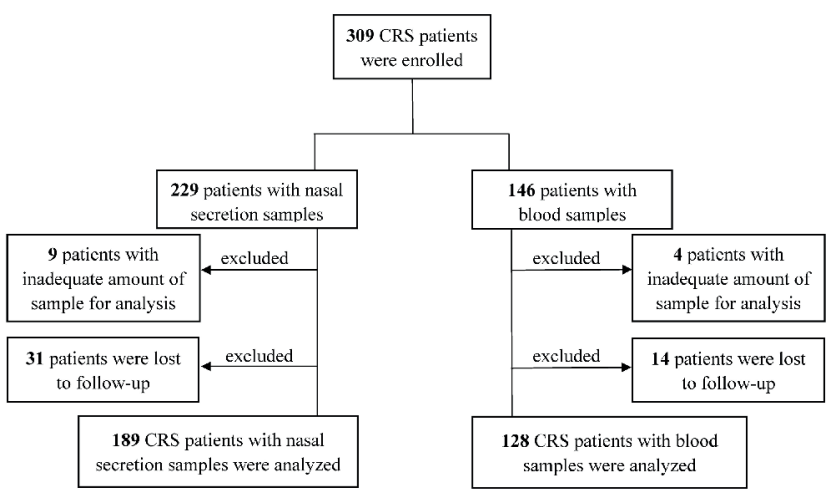

Figure 1. The flow diagram for enrolled chronic rhinosinusitis patients in nasal secretion sample group and blood sample group. CRS, chronic rhinosinusitis.

on bootstrapped data set ${ }^{(26)}$. RF analysis provided a variable importance plot measured by mean decrease Gini index to rank the importance of the predictor for difficult-to-treat CRS ${ }^{(27)}$. The analysis for CART and RF were performed in R (R Development Core Team).

\section{Results}

Study cohort

In this study, 309 CRS patients were finally enrolled from January 2015 to December 2017. After excluding patients with inadequate amount of sample or lost to follow-up, 189 patients with nasal secretion samples and 128 patients with blood plasma samples were finally analysed (Figure 1). In both nasal secretion and blood sample groups, no significant difference in demographic or clinical characteristics was noted between the patients finally analysed and those excluded (Table E3 and Table E4). In addition, there was no significant difference in baseline clinical characteristics between finally analysed patients in nasal secretion sample group and blood sample group (Table E5).

\section{Clinical characteristics and inflammatory biomarkers in} nasal secretions in the cohort with nasal secretion sample In the cohort with nasal secretion sample, after 1 year of followup, 40 of 189 CRS patients (accounting for 21\%) were diagnosed as difficult-to-treat CRS. Baseline clinical characteristics of patients with and without difficult-to-treat CRS were shown in Table 1. There were no significant differences regarding the age and gender between the patients with or without difficult-totreat CRS.

Compared with non-difficult-to-treat CRS patients, atopy, and allergic rhinitis and asthma comorbidity were more commonly found in difficult-to-treat CRS patients. Patients with difficult-totreat CRS were more frequently to have a history of prior sinus surgery and nasal polyps than patients with non-difficult-totreat CRS.
Patients with difficult-to-treat CRS had greater disease severity as reflected by subjective symptoms, nasal endoscopy, and sinus CT scans. Difficult-to-treat CRS patients had more severe nasal obstruction and hyposmia than non-difficult-to-treat CRS patients. Moreover, patients with difficult-to-treat CRS presented with higher peripheral blood eosinophil levels in comparison to patients with non-difficult-to-treat CRS.

To investigate immunoprofiles associated with difficult-to-treat CRS, we detected representative type 1, type 2 and type 17 cytokines, proinflammatory cytokines, chemokines, tissue remodelling cytokines, and immunoglobulins, that have been previously implicated in the pathogenesis of CRS ${ }^{(2,3)}$. Patients with difficultto-treat CRS had significantly higher levels of IL-9, monocyte chemoattractant protein (MCP)-1, macrophage inflammatory protein (MIP)-1a, MIP-1 $\beta$, IgE and chemokine (C-C motif) ligand 17 (CCL17) and lower level of Regulated on activation, normal T-cell expressed and secreted (RANTES) compared with patients with non-difficult-to-treat CRS (Table 2).

\section{Creation of prediction model for difficult-to-treat CRS by} CART analysis

To establish a prediction model comprehensively evaluating clinical factors and nasal secretion biomarkers to stratify CRS patients undergoing ESS, we performed CART analysis. The classification tree algorithm relied on the variables that exhibited significant differences between the difficult-to-treat and non-difficult-to-treat CRS patients (for clinical factors: $\mathrm{P}<0.01$; for nasal secretion biomarkers: $P<0.05$ ). Figure 2 presented the resulting pruned classification tree for the difficult-to-treat CRS. Four variables were identified as important predictors of CRS outcome: CCL17, VAS score of hyposmia, allergic rhinitis comorbidity, and MIP-1 $\beta$. The application of the CART analysis led to the definition of five CRS subgroups. In the classification tree, the first node represented the total CRS patients with nasal secretion samples $(n=189)$, then it was divided into two subgroups, based on the cut-off value of CCL17 level. CCL17 level $\geq 1.4 \mathrm{pg} / \mathrm{mg}$ was the most important variable in predicting difficult-to-treat CRS, with odds ratio (OR) of 49.0 (95\%Cl: 10.6226.7). The VAS score of smell loss was found as another important predictor. The subgroup of patients with $\mathrm{CCL} 17<1.4 \mathrm{pg} /$ $\mathrm{mg}$ and loss of smell VAS score $<8$ accounted for $60 \%(113 / 189)$ of the cohort, and $97 \%(110 / 113)$ patients in this subgroup were non-difficult-to-treat CRS. For patients with loss of smell VAS score $\geq 8$, allergic rhinitis comorbidity further increased the risk of poor outcome, with OR of 27.0 (95\%Cl: 3.1-235.7). MIP-1 $\beta$ was found associated with difficult-to-treat CRS. For patients with CCL $17<1.4 \mathrm{pg} / \mathrm{mg}$, loss of smell VAS score $\geq 8$, absence of allergic rhinitis comorbidity, and MIP- $1 \beta \geq 53 \mathrm{pg} / \mathrm{mg}, 10$ of 12 (83\%) patients were diagnosed as difficult-to-treat CRS (OR 85.0, $95 \% \mathrm{Cl}: 10.6-682.4)$. In the subgroup of patients with $\mathrm{CCL} 17<1.4$ $\mathrm{pg} / \mathrm{mg}$, loss of smell VAS score $\geq 8$, absence of allergic rhinitis co- 
Table 1. Baseline characteristics of patients with and without difficult-to-treat CRS in the cohort with nasal secretion sample.

\begin{tabular}{|c|c|c|c|}
\hline & $\begin{array}{l}\text { Non-difficult-to-treat CRS } \\
\qquad(n=149)\end{array}$ & $\begin{array}{l}\text { Difficult-to-treat CRS } \\
\qquad(n=40)\end{array}$ & P value \\
\hline Gender, male (\%) & $90(60.40)$ & $29(72.50)$ & 0.198 \\
\hline Age (y) & $41.0(25.0-50.0)$ & $43.0(29.0-48.0)$ & 0.878 \\
\hline Atopy, n (\%) & $55(36.91)$ & $22(55.00)$ & 0.039 \\
\hline$A R, n(\%)$ & $20(13.42)$ & $13(32.50)$ & 0.005 \\
\hline Asthma, n (\%) & $8(5.37)$ & $7(17.50)$ & 0.020 \\
\hline Prior surgery, n (\%) & 35 (23.49) & $17(42.50)$ & 0.027 \\
\hline Nasal polyps, n (\%) & $97(65.10)$ & $36(90.00)$ & 0.002 \\
\hline Disease duration (y) & $3.0(1.0-10.0)$ & $4.5(1.0-12.0)$ & 0.211 \\
\hline Nasal obstruction VAS score & $6.0(4.0-8.0)$ & $8.0(6.0-10.0)$ & 0.013 \\
\hline Rhinorrhoea VAS score & $5.0(3.0-7.0)$ & $6.0(2.0-8.0)$ & 0.693 \\
\hline Headache VAS score & $3.0(0-6.0)$ & $3.0(0-6.0)$ & 0.997 \\
\hline Facial pain VAS score & $0(0-3.0)$ & $1.0(0-5.0)$ & 0.119 \\
\hline Loss of smell VAS score & $5.0(2.0-8.0)$ & $8.0(5.0-10)$ & $<0.001$ \\
\hline Total symptom VAS score & $20.0(14.0-27.0)$ & $24.0(19.0-32.0)$ & 0.017 \\
\hline Overall burden VAS score & $6.0(4.0-8.0)$ & $7.0(5.0-8.0)$ & 0.399 \\
\hline Nasal polyp score & $2.0(0-4.0)$ & $4.0(2.0-6.0)$ & $<0.001$ \\
\hline Bilateral CT score & $13.0(7.0-19.0)$ & $21.0(16.0-24.0)$ & $<0.001$ \\
\hline Ethmoid sinus score & $5.0(2.0-7.0)$ & $7.0(5.0-8.0)$ & 0.014 \\
\hline Maxillary sinus score & $2.0(2.0-3.0)$ & $3.0(2.0-4.0)$ & 0.022 \\
\hline E/M ratio & $1.67(1.40-2.00)$ & $1.80(1.60-2.00)$ & 0.974 \\
\hline $\mathrm{PE} / \mathrm{AE}$ ratio & $1.00(0.75-1.00)$ & $1.00(0.80-1.00)$ & 0.539 \\
\hline Total endoscopic score & $6.0(5.0-8.0)$ & $9.0(7.0-11.0)$ & 0.013 \\
\hline Blood leukocyte count (×109/L) & $5.93(4.91-7.25)$ & $6.13(5.32-7.40)$ & 0.183 \\
\hline Blood neutrophil count $\left(\times 10^{9} / \mathrm{L}\right)$ & $3.26(2.74-4.07)$ & $3.33(2.93-4.10)$ & 0.581 \\
\hline Blood neutrophil ratio (\%) & $52.00(45.65-56.95)$ & $53.65(48.38-61.98)$ & 0.473 \\
\hline Blood lymphocyte count (×109/L) & $2.05(1.68-2.47)$ & $1.91(1.48-2.45)$ & 0.409 \\
\hline Blood lymphocyte ratio (\%) & $35.70(30.40-41.70)$ & $33.10(27.55-39.70)$ & 0.061 \\
\hline Blood eosinophil count $\left(\times 10^{9} / \mathrm{L}\right)$ & $0.17(0.11-0.31)$ & $0.31(0.15-0.56)$ & 0.003 \\
\hline Blood eosinophil ratio (\%) & $2.85(1.80-4.75)$ & $4.65(1.98-9.15)$ & 0.008 \\
\hline Blood monocyte count $\left(\times 10^{9} / L\right)$ & $0.43(0.35-0.54)$ & $0.45(0.36-0.55)$ & 0.375 \\
\hline Blood monocyte ratio (\%) & $7.30(6.38-8.73)$ & $7.00(6.20-8.50)$ & 0.275 \\
\hline
\end{tabular}

Data are presented as medians (inter-quartile ranges) or $n$ (\%). Bold indicates statistical significance (P < 0.05). CRS, chronic rhinosinusitis; AR, allergic rhinitis; VAS, visual analog scale; $C T$, computed tomography; $E$, ethmoid sinus score; $M$, maxillary sinus score; $A E$, anterior ethmoid score; $P E$, posterior ethmoid score

morbidity, and MIP-1 $\beta<53 \mathrm{pg} / \mathrm{mg}$, 94\% (34/36) of patients were non-difficult-to-treat CRS. The overall accuracy of this prediction model achieved $94 \%$.

RF analysis further confirmed predictive importance of variables identified in the CART analysis (Figure 3). Each variable was ranked by the order of mean decrease Gini index. A higher mean decrease Gini value represents a higher variable importance ${ }^{(28)}$. In consistent with CART analysis, CCL17 was the most important variable for CRS outcome. Among clinical factors, loss of smell
VAS score and allergic rhinitis comorbidity were two important variables. MIP-1 $\beta$ and RANTES had similar predictive importance in the RT analysis.

We also tried to develop a classification tree with clinical factors only or nasal secretion biological markers only. Nevertheless, we failed to generate a better prediction model (data not shown).

Clinical characteristics and inflammatory biomarkers in plasma in the cohort with blood sample 
Table 2. Nasal secretion biomarkers in patients with and without difficult-to-treat CRS.

\begin{tabular}{|c|c|c|c|}
\hline & $\begin{array}{l}\text { Non-difficult-to-treat CRS } \\
\qquad(n=149)\end{array}$ & $\begin{array}{l}\text { Difficult-to-treat CRS } \\
\qquad(\mathrm{n}=\mathbf{4 0})\end{array}$ & P value \\
\hline IL-1 $\beta$ (pg/mg) & $8.43(3.21-21.42)$ & $13.64(3.88-36.91)$ & 0.053 \\
\hline IL-1Ra (pg/mg) & $631.70(371.77-1128.22)$ & $488.39(267.32-844.40)$ & 0.056 \\
\hline IL-2 (pg/mg) & $0.88(0.62-1.27)$ & $0.79(0.59-1.23)$ & 0.501 \\
\hline $\mathrm{IL}-4$ (pg/mg) & $0.66(0.35-1.10)$ & $0.57(0.38-1.07)$ & 0.854 \\
\hline IL-5 (pg/mg) & $1.17(0.56-2.10)$ & $1.04(0.45-2.98)$ & 0.965 \\
\hline IL-6 (pg/mg) & $14.33(6.54-33.26)$ & $18.48(7.47-73.61)$ & 0.089 \\
\hline IL-7 (pg/mg) & $7.72(5.27-11.33)$ & $8.33(4.94-12.66)$ & 0.907 \\
\hline IL-8 (pg/mg) & 737.89 (379.21-1369.49) & $734.66(431.00-1543.82)$ & 0.935 \\
\hline IL-9 (pg/mg) & $3.46(1.39-6.42)$ & $4.71(2.41-8.93)$ & 0.022 \\
\hline IL-10 (pg/mg) & $6.09(4.20-9.90)$ & $5.50(4.04-8.21)$ & 0.280 \\
\hline IL-12 (pg/mg) & $21.93(12.78-40.11)$ & $16.26(9.83-28.61)$ & 0.051 \\
\hline IL-13 (pg/mg) & $5.33(3.40-9.02)$ & $6.54(2.99-11.74)$ & 0.417 \\
\hline IL-15 (pg/mg) & $5.04(3.37-6.76)$ & $5.22(3.91-6.87)$ & 0.468 \\
\hline IL-17A (pg/mg) & $4.76(2.89-8.32)$ & $5.52(4.25-8.35)$ & 0.195 \\
\hline IL-22 (pg/mg) & $1.78(1.20-3.10)$ & $2.16(1.06-3.55)$ & 0.915 \\
\hline IL-25 (pg/mg) & $0.16(0.08-0.34)$ & $0.12(0.07-0.27)$ & 0.484 \\
\hline IL-33 (ng/mg) & $1.16(0.46-2.10)$ & $1.69(1.04-3.37)$ & 0.052 \\
\hline Eotaxin (pg/mg) & $15.68(6.56-32.54)$ & $18.81(7.13-39.77)$ & 0.595 \\
\hline bFGF (pg/mg) & $31.24(16.84-62.65)$ & $31.22(17.98-39.77)$ & 0.802 \\
\hline G-CSF (pg/mg) & $586.92(186.54-2246.26)$ & $636.04(209.46-3572.47)$ & 0.423 \\
\hline GM-CSF (pg/mg) & $52.45(26.00-89.76)$ & $41.17(20.15-70.77)$ & 0.121 \\
\hline IFN- $\gamma(\mathrm{pg} / \mathrm{mg})$ & $27.88(19.53-40.71)$ & $25.79(17.55-38.06)$ & 0.433 \\
\hline IP-10 (ng/mg) & $20.81(8.43-45.61)$ & $20.81(9.27-46.22)$ & 0.927 \\
\hline MCP-1 (pg/mg) & $9.12(5.34-18.29)$ & $16.15(10.40-34.80)$ & 0.002 \\
\hline MIP-1a (pg/mg) & $1.93(0.95-3.55)$ & $3.83(1.33-11.22)$ & 0.004 \\
\hline PDGF-BB (pg/mg) & $8.82(1.70-21.38)$ & $11.71(3.79-27.04)$ & 0.412 \\
\hline MIP-1 $\beta$ (pg/mg) & $29.16(12.91-50.41)$ & $54.05(30.24-90.40)$ & $<0.001$ \\
\hline RANTES (pg/mg) & $187.81(105.57-376.87)$ & $66.77(35.31-190.50)$ & $<0.001$ \\
\hline TNF-a (pg/mg) & $5.78(2.41-10.52)$ & $6.21(3.04-13.07)$ & 0.352 \\
\hline VEGF (pg/mg) & $413.07(195.82-692.71)$ & $325.51(127.13-666.23)$ & 0.214 \\
\hline $\operatorname{lgG} 1(\mathrm{ng} / \mathrm{mg})$ & $16.93(11.76-32.29)$ & $21.96(12.14-42.92)$ & 0.400 \\
\hline $\operatorname{lgG} 2$ (ng/mg) & $14.92(10.08-22.78)$ & $16.97(11.59-25.78)$ & 0.278 \\
\hline $\operatorname{lgG} 3(\mathrm{ng} / \mathrm{mg})$ & $5.71(2.18-10.96)$ & 3.37 (2.46-10.49) & 0.951 \\
\hline $\operatorname{lgG} 4$ (ng/mg) & $1.54(0.53-4.68)$ & $2.61(1.50-6.89)$ & 0.064 \\
\hline $\lg \mathrm{A}(\mathrm{ng} / \mathrm{mg})$ & $13.53(9.21-21.78)$ & $12.49(10.42-32.75)$ & 0.298 \\
\hline $\lg M(n g / m g)$ & $3.87(2.18-6.20)$ & $4.31(2.65-8.68)$ & 0.115 \\
\hline $\lg E(p g / m g)$ & $0.11(0.03-0.29)$ & $0.40(0.10-1.94)$ & 0.004 \\
\hline $\mathrm{CCL} 17$ (pg/mg) & $0.32(0.16-0.52)$ & $0.81(0.34-1.84)$ & 0.002 \\
\hline TSLP (pg/mg) & $0.97(0.45-1.83)$ & $0.92(0.62-2.77)$ & 0.943 \\
\hline
\end{tabular}

Data are presented as medians (inter-quartile ranges). Bold indicates statistical significance ( $<0.05)$. IL, interleukin; IL-1 Ra, IL-1 receptor antagonist; bFGF, basic fibroblast growth factor; G-CSF, granulocyte colony-stimulating factor; GM-CSF, granulocyte-macrophage colony-stimulating factor; IFN- $\gamma$, interferon- $\gamma ;$ IP-10, IFN- - -induced protein 10; MCP-1, monocyte chemoattractant protein-1; MIP, macrophage inflammatory protein; PDGF-BB, platelet-derived growth factor-BB; RANTES, regulated on activation, normal T-cell expressed and secreted; TNF-a, tumor necrosis factor a; VEGF, vascular endothelial growth factor; Ig, immunoglobulin; CCL: chemokine (C-C motif) ligand; TSLP, thymic stromal lymphopoietin. 


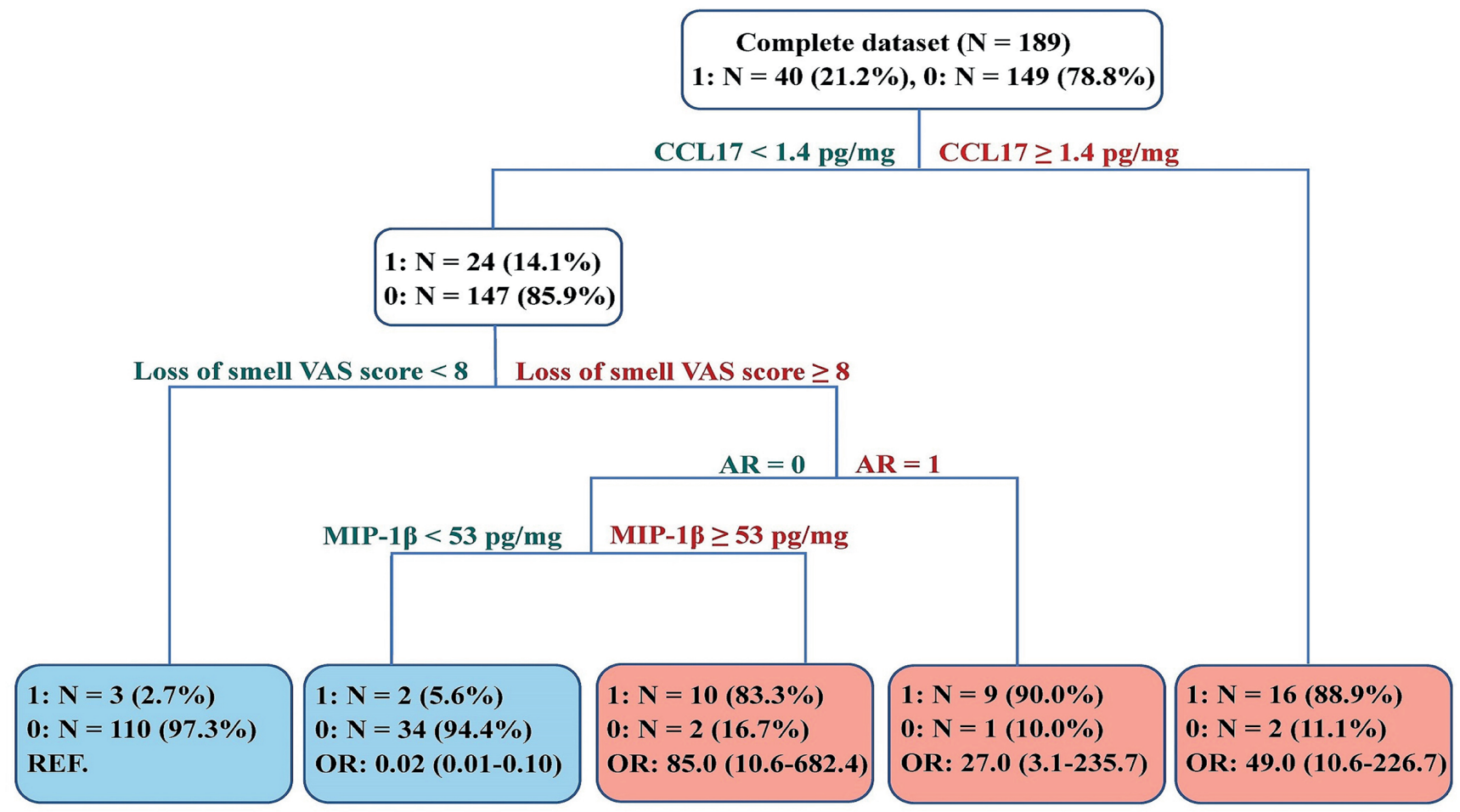

Figure 2. Classification tree for difficult-to-treat chronic rhinosinusitis. Presence or absence of difficult-to-treat chronic rhinosinusitis = " 1 " or "0". "AR = 1 or $0^{\prime \prime}$ represents with or without allergic rhinitis. Odds ratios (OR) with $95 \%$ confidence interval are given in comparison with the CCL17-low, loss of smell VAS score-low, AR-negative, and MIP-1 $\beta$-low group. CCL17, chemokine (C-C motif) ligand 17; VAS, visual analogue scale; MIP-1 $\beta$, macrophage inflammatory protein-1 $\beta$.

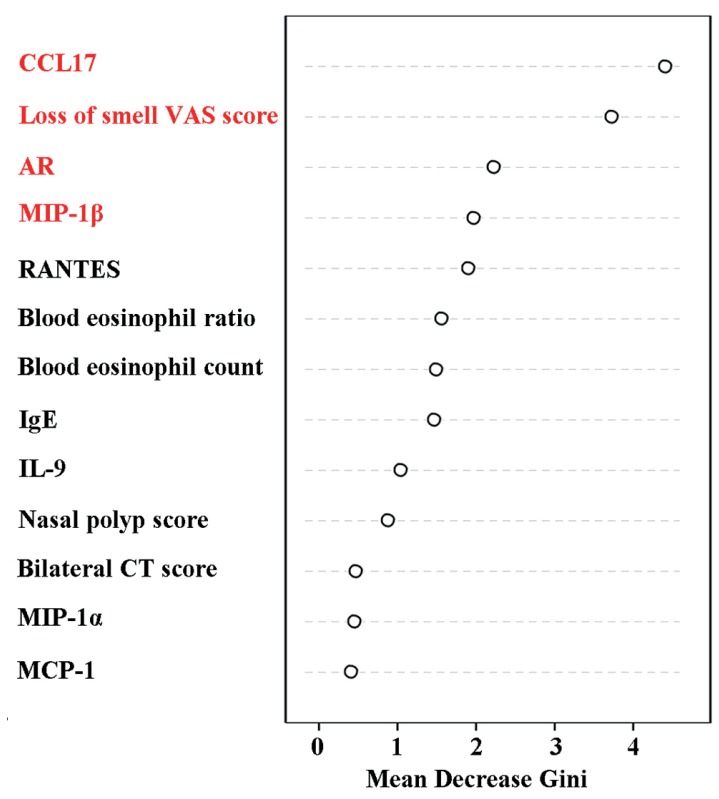

Figure 3. Random forest analysis of predictors for difficult-to-treat chronic rhinosinusitis in the cohort with nasal secretion sample. Mean Decrease Gini represents the relative predictive importance of each variable. CCL17: chemokine (C-C motif) ligand 17; VAS, visual analogue scale; AR, allergic rhinitis; MIP-1 $\beta$, macrophage inflammatory protein-1 $\beta$; RANTES, regulated on activation, normal T-cell expressed and secreted; IL, interleukin; MCP-1, monocyte chemoattractant protein-1.
In the cohort with blood plasma sample, after 1 year of followup, 31 of the 128 CRS patients (accounting for 24.2\%) were diagnosed as difficult-to-treat CRS. In agreement with the cohort with nasal secretion sample, difficult-to-treat CRS patients had higher proportions of atopy, allergic rhinitis and asthma comorbidity, prior surgery and nasal polyps, higher VAS scores of smell loss, more severe endoscopic and CT findings, and higher blood eosinophil levels (Table E6). However, with regard to plasma biomarkers, there was no significant difference between the difficult-to-treat and non-difficult-to-treat CRS patients (Table E7). We further performed logistic regression analysis, and again none of the plasma biomarkers were found associated with difficult-to-treat CRS (data not shown).

\section{Discussion}

Despite decades of therapeutic and surgical refinements, CRS still remains a refractory disease with a high morbidity and recurrence rate. Thus, identifying patients with high risk of uncontrolled disease may have great clinical value for personalized treatments. The objective of this study was to identify important clinical and noninvasive biological predictors of difficult-to-treat CRS.

In this study, four baseline variables including nasal secretion CCL17 level, VAS score of hyposmia, allergic rhinitis comorbidity, 
and nasal secretion MIP-1 $\beta$ level were identified as important predictors of difficult-to-treat CRS by CART analysis. CCL17, the most powerful discriminator, was placed on the root of the classification tree. For cases with CCL17 $\geq 1.4 \mathrm{pg} / \mathrm{mg}$, eighty nine percent (16/18) of them were diagnosed as difficult-to-treat CRS. CCL17 is predominantly produced by epithelial cells in upper and lower airways ${ }^{(29)}$. By interacting with CC chemokine receptor 4, CCL17 selectively induces the migration of $\mathrm{TH} 2$ lymphocytes into allergic inflammatory sites ${ }^{(30)}$. CCL17 expression was found elevated in nasal polyps, even as compared to the nasal mucosa of patients with allergic rhinitis ${ }^{(31)}$. The association between the CCL17 level and CRS outcome has not been noted before. Here we show that CCL17 level in nasal secretions might be a promising biomarker for predicting difficult-to-treat CRS. Another important finding of this study was the impact of baseline hyposmia severity on CRS prognosis. There was a positive association between baseline CCL17 level in nasal secretions and difficult-to-treat CRS. However, for patients with low CCL17 levels $(<1.4 \mathrm{pg} / \mathrm{mg})$, the association was first influenced by hyposmia. Patients with severe hyposmia (loss of smell VAS score $\geq$ 8) had higher risk of poor outcome than patients who had better olfactory function. Majority of patients $(97 \% ; 110 / 113)$ with low levels of CCL17 and moderate/mild hyposmia (loss of smell VAS score $<8$ ) had a good outcome after 1 year of follow-up. Polyps and inflammatory mucosa might cause nasal obstruction and impaired airflow into the olfactory cleft ${ }^{(32)}$. Therefore, severe hyposmia is likely a sign of severe local lesion. Here, we also found that VAS scores of hyposmia were positively correlated with nasal obstruction scores, nasal endoscopic scores and CT scores (data not shown). Previous reports have indicated that hyposmia was significantly associated with the type 2 inflammation, and identified as an early sign of nasal polyp recurrence after ESS ${ }^{(33)}$. Allergic rhinitis comorbidity further increased the risk of poor outcome in patients with low CCL17 levels and severe olfactory dysfunction, and ninety percent (9/10) patients of this subgroup were diagnosed as difficult-to-treat CRS. Allergic rhinitis has been found associated with difficult-to-treat CRS in our previous study ${ }^{(9)}$. It suggests that a detailed patient history collection and physical examination with respect to symptoms and comorbidity could be of great value for predicting treatment response in daily clinical practice.

Our previous study showed that nasal mucosal MIP- $1 \beta$ was an independent predictor of difficult-to-treat CRS ${ }^{(9)}$. Here, higher nasal secretion MIP-1 $\beta$ levels ( $\geq 53 \mathrm{pg} / \mathrm{mg}$ ) increased the likelihood of poor prognosis for the patients with low CCL17 levels, severe hyposmia, and absence of allergic rhinitis comorbidity. In this subgroup, eighty three percent (10/12) of patients were diagnosed as difficult-to-treat CRS. MIP-1 $\beta$ functions as a chemokine for CCR5-expressing cells and induces eosinophil migration into local inflammatory site ${ }^{(34)}$. Activated eosinophils can further produce MIP-1 $\beta$, therefore forming a positive feedback loop ${ }^{(34)}$.
MIP-1 $\beta$ has also been found associated with reduced response to nasal corticosteroid sprays in CRS patients with concomitant asthma ${ }^{(35)}$.

Previously, we investigated the predictive efficacy of nasal mucosal biomarkers for CRS outcomes and found that IL-10 and MIP-1 $\beta$ were independent predictors of difficult-to-treat CRS (9). However, sinonasal mucosa could only be obtained invasively by surgery or biopsy. In contrast, the collection of nasal secretions is noninvasive and convenient, and can be implemented in both out-patient clinic and operation room. Since little is known about the correlations between nasal secretions derived biomarkers and CRS postoperative outcomes, our results extended the current heterogeneous evidence on difficult-to-treat CRS predictors and provide the possibility to predict the treatment outcome by a more practical approach.

With regard to difficult-to-treat CRS, the previously reported prediction models were mostly developed by multivariate logistic regression analysis and were difficult to be implemented in clinical practice, especially for non-statisticians. For the first time, the present study used a CART analysis to comprehensively evaluate the hierarchy of clinical and noninvasive molecular predictors associated with CRS outcomes. A classification tree with visualizable risk factors was generated and the results could be easily interpreted for clinical application. The overall accuracy of this prediction model was $94 \%$, markedly higher than that (77.3\%) of our previous model generated by multivariate logistic regression analysis of nasal mucosal biomarkers. In addition, we performed RF analysis to verify the predictive importance of variables and consistently found that CCL17 level, VAS score of hyposmia, allergic rhinitis comorbidity, and MIP-1 $\beta$ level were the four most important variables, confirming the results of CART analysis.

Peripheral blood samples can be easily collected and quantified. In line with previous reports ${ }^{(36)}$, blood eosinophilia was found associated with CRS poor outcome (Table 1 and Table E6). However, it was not included in the classification tree (Figure 2). The plasma biomarker expression profile of difficult-to-treat CRS resembled that of non-difficult-to-treat CRS (Table E7). One possible explanation is that CRS is more likely a localised inflammatory disorder and biomarkers in peripheral blood may not have enough resolution to capture the difference at mucosal sites in CRS patients with different outcomes. It is also possible that there might exist other plasma biomarkers which were not covered in our study, but could predict CRS outcome.

Our study has several limitations. Given the limited number of patients with difficult-to-treat CRS, we were unable to divide our patients into training and validation set. In addition, in our study, in order to avoid the interference of steroid treatment on cytokine levels, the patients receiving preoperative steroids were excluded. However, in the real-world setting, patients may receive steroids before surgery. Preoperative steroid treatments 
obviously influence the treatment outcomes of patients and thus the establishment of the prediction models. We therefore have to emphasize that the prediction model established based on our current cohort may not apply to patients in other healthcare systems where preoperative steroids are commonly used. The generalization of our model is definitely required to be validated in future. In this study, although we included 39 CRS relevant biomarkers, there is no doubt that we may miss some potential biomarkers, such as periostin and eosinophilic cationic protein. Nevertheless, at this stage, our intention is not to provide a ready to implement clinical tool with definitive cut-off values and the best predictive efficiency, but to provide a possibility that an easily interpretable tool can be developed and is promising for clinical application.

\section{Conclusion}

This is the first known study to subgroup patients into risk groups for difficult-to-treat CRS via a classification tree, which was composed of a panel of clinical and noninvasive biological markers. High nasal secretion CCL17 and MIP-1 $\beta$ levels, severe hyposmia and allergic rhinitis comorbidity were found important predictors of difficult-to-treat CRS. These findings may assist physicians in predicting CRS treatment response before surgery in daily clinical practice. For patients with a high risk of poor outcome, physicians can manage their diseases with careful follow-up visits and delicate treatments, such as glucocorticoid nasal irrigation, steroid elute implant, and more extensive surgery. However, it should be emphasized that since only patients without preoperative steroid treatments were included in this study, the generalization of our model in other patient populations should be considered with caution.

\section{Acknowledgements}

This study was supported by National Key R\&D Program of China (2018YFC0116800), National Natural Science Foundation of China (NSFC) grants 81630024 and 8192010801 (ZL), and 81700893 (BL), Hubei Province Natural Science Foundation grants 2017 CFA016 (ZL).

\section{Authorship contribution}

CLG and BL performed bio-plex study, statistical analysis, and prepared the manuscript. JXLand LP collected the samples and recorded the baseline and follow up information. ZL designed the study, did endoscopic examination and surgery, and prepared the manuscript.

\section{Conflict of interest}

None

\section{References}

1. Fokkens WJ, Lund VJ, Mullol J, et al. European Position Paper on Rhinosinusitis and Nasal Polyps 2012. Rhinol Suppl. 2012;23:3:1-298.

2. Liao B, Liu JX, Li ZY, et al. Multidimensiona endotypes of chronic rhinosinusitis and their association with treatment outcomes. Allergy. 2018;73:1459-1469.

3. Tomassen P, Vandeplas G, Van Zele T, et al. Inflammatory endotypes of chronic rhinosinusitis based on cluster analysis of biomarkers. J Allergy Clin Immunol. 2016;137:14491456 e 1444.

4. Tao X, Chen F, Sun Y, et al. Prediction models for postoperative uncontrolled chronic rhinosinusitis in daily practice. Laryngoscope. 2018;128:2673-2680.

5. Sella GCP, Tamashiro E, Sella JA, et al Asthma is the Dominant Factor for Recurrence in Chronic Rhinosinusitis. J Allergy Clin Immunol Pract. 2020;8:302-309.

6. Van Zele T, Holtappels G, Gevaert P, Bachert C. Differences in initial immunoprofiles between recurrent and nonrecurrent chronic rhinosinusitis with nasal polyps. Am J Rhinol Allergy. 2014;28:192-198.

7. Lou H, Meng Y, Piao Y, Wang C, Zhang L, Bachert C. Predictive significance of tissue eosinophilia for nasal polyp recurrence in the Chinese population. Am J Rhinol Allergy. 2015;29:350-356.

8. Qi S, Yan B, Liu C, Wang C, Zhang L.
Predictive significance of Charcot-Leyden Crystal mRNA levels in nasal brushing for nasal polyp recurrence. Rhinology. 2020;58:166-174.

9. Liao B, Liu JX, Guo CL, Li ZY, Pan L, Liu Z. A panel of clinical and biological markers predict difficult-to-treat chronic rhinosinusitis. Allergy. 2020;75:946-949.

10. Weibman AR, Huang JH, Stevens WW, et al. A prospective analysis evaluating tissue biopsy location and its clinical relevance in chronic rhinosinusitis with nasal polyps. Int Forum Allergy Rhinol. 2017;7:1058-1064.

11. Asmar MH, Gaudreau A, Maniakas A, Mfuna Endam L, Desrosiers M. An Evaluation of SPARC Protein as a Serum Biomarker of Chronic Rhinosinusitis. Otolaryngol Head Neck Surg. 2019;160:158-164.

12. Chowdhury NI, Li P, Chandra RK, Turner JH. Baseline mucus cytokines predict 22-item Sino-Nasal Outcome Test results after endoscopic sinus surgery. Int Forum Allergy Rhinol. 2019:10:15-22.

13. Liu C, Yan B, Qi S, Zhang Y, Zhang L, Wang C. Predictive Significance of CharcotLeyden Crystals for Eosinophilic Chronic Rhinosinusitis With Nasal Polyps. Am J Rhinol Allergy. 2019;33:671-680.

14. Chester R, Khondoker M, Shepstone L, Lewis JS, Jerosch-Herold C. Self-efficacy and risk of persistent shoulder pain: results of a Classification and Regression Tree (CART) analysis. Br J Sports Med. 2019;53:825-834.
15. Loh $W-Y$. Classification and regression trees. WIREs Data Mining and Knowledge Discovery. 2011;1:14-23.

16. Leffler J, Read JF, Jones AC, et al. Progressive increase of FceRl expression across several PBMC subsets is associated with atopy and atopic asthma within school-aged children. Pediatr Allergy Immunol. 2019;30:646-653.

17. Wang $Y$, Chen $H$, Zhu $R$, et al. Allergic Rhinitis Control Test questionnaire-driven stepwise strategy to improve allergic rhinitis control: a prospective study. Allergy. 2016;71:1612-1619.

18. Brozek JL, Bousquet J, Agache I, et al. Allergic Rhinitis and its Impact on Asthma (ARIA) guidelines-2016 revision. J Allergy Clin Immunol. 2017;140:950-958.

19. Boulet L-P, Reddel HK, Bateman E, Pedersen S, FitzGerald JM, O'Byrne PM. The Global Initiative for Asthma (GINA): 25 years later. Eur Resp J. 2019:54:1900598.

20. Lund VJ, Kennedy DW. Staging for rhinosinusitis. Otolaryngol Head Neck Surg. 1997;117:S35-40.

21. Hu Y, Cao PP, Liang GT, Cui YH, Liu Z. Diagnostic significance of blood eosinophil count in eosinophilic chronic rhinosinusitis with nasal polyps in Chinese adults. Laryngoscope. 2012;122:498-503.

22. Liao B, Cao PP, Zeng M, et al. Interaction of thymic stromal lymphopoietin, IL-33, and their receptors in epithelial cells in eosinophilic chronic rhinosinusitis with nasal pol- 
yps. Allergy. 2015;70:1169-1180

23. Liu JX, Liao B, Yu QH, et al. The IL-37-Mex3BToll-like receptor 3 axis in epithelial cells in patients with eosinophilic chronic rhinosinusitis with nasal polyps. J Allergy Clin Immunol. 2020;145:160-172.

24. van der Veen J, Seys SF, Timmermans M, et al. Real-life study showing uncontrolled rhinosinusitis after sinus surgery in a tertiary referral centre. Allergy. 2017;72:282-290.

25. Houser B. Bio-Rad's Bio-Plex(R) suspension array system, XMAP technology overview. Arch Physiol Biochem. 2012;118:192-196.

26. Breiman L. Random Forests. Machine Learning. 2001;45:5-32.

27. Henrard S, Speybroeck N, Hermans C. Classification and regression tree analysis vs. multivariable linear and logistic regression methods as statistical tools for studying haemophilia. Haemophilia. 2015;21:715722.

28. Kuhn S, Egert B, Neumann S, Steinbeck C Building blocks for automated elucidation of metabolites: machine learning methods for NMR prediction. BMC Bioinformatics. 2008;9:400

29. Sekiya T, Miyamasu M, Imanishi M, et al. Inducible expression of a Th2-type CC chemokine thymus- and activation-regulat- ed chemokine by human bronchial epithelial cells. J Immunol. 2000;165:2205-2213.

30. Leung TF, Wong CK, Chan IH, Ip WK, Lam CW, Wong GW. Plasma concentration of thymus and activation-regulated chemokine is elevated in childhood asthma. J Allergy Clin Immunol. 2002;110:404409.

31. Kimura S, Pawankar R, Mori S, et al. Increased expression and role of thymic stromal lymphopoietin in nasal polyposis. Allergy Asthma Immunol Res. 2011;3:186193.

32. Schlosser RJ, Mulligan JK, Hyer JM, Karnezis TT, Gudis DA, Soler ZM. Mucous Cytokine Levels in Chronic Rhinosinusitis-Associated Olfactory Loss. JAMA Otolaryngol Head Neck Surg. 2016;142:731-737.

33. Bakhshaee $M$, Sharifian MR, Ghazizadeh $A H$ Nahid K, Jalaeian Samani K. Smell Decline as a good Predictor of Sinonasal Polyposis Recurrence after Endoscopic Surgery. Iran J Otorhinolaryngol. 2016;28:125-134.

34. Kobayashi Y, Konno Y, Kanda A, et al. Critical role of CCL4 in eosinophil recruitment into the airway. Clin Exp Allergy. 2019;49:853860.

35. Kobayashi Y, Kanda A, Yun Y, et al. Reduced Local Response to Corticosteroids in
Eosinophilic Chronic Rhinosinusitis with Asthma. Biomolecules. 2020;10(2):326.

36. Brescia G, Barion U, Zanotti C, Giacomelli $\mathrm{L}$, Martini A, Marioni $\mathrm{G}$. The prognostic role of serum eosinophil and basophil levels in sinonasal polyposis. Int Forum Allergy Rhinol. 2017;7:261-267.

Zheng Liu, MD, PhD

Department of Otolaryngology

Head and Neck Surgery

Tongji Hospital

Tongji Medical College

Huazhong University of Science and

Technology

No. 1095 Jiefang Avenue

Wuhan 430030

P.R. China

E-mail: zhengliuent@hotmail.com

This paper contains supplementary materials online: at www.rhinologyjournal.org 


\section{SUPPLEMENTARY DATA}

Table E1. Assessment of clinical control of CRS according to the European Position Paper on Rhinosinusitis and Nasal Polyps 2012 (1).

\begin{tabular}{|c|c|c|c|}
\hline Characteristic & $\begin{array}{l}\text { Controlled } \\
\text { (all of the following) }\end{array}$ & $\begin{array}{l}\text { Partly Controlled } \\
\text { (at least one present) }\end{array}$ & $\begin{array}{l}\text { Uncontrolled } \\
\text { (three or more features of partly } \\
\text { controlled CRS) }\end{array}$ \\
\hline Nasal blockage & Not present or not bothersome & Present on most days of the week ${ }^{2}$ & \\
\hline Rhinorrhoea/postnasal drip & Little and mucous & $\begin{array}{l}\text { Mucopurulent on most days of the } \\
\text { week }^{2}\end{array}$ & \\
\hline Facial pain/headache & Not present or not bothersome & Present $^{2}$ & \\
\hline Loss of smell & Not present or not bothersome & Present $^{2}$ & \\
\hline Sleep disturbance or fatigue & Not or only slightly present & Present $^{2}$ & \\
\hline Nasal endoscopy (if available) & Healthy or almost healthy mucosa & $\begin{array}{l}\text { Diseased mucosa (nasal polyps, } \\
\text { mucopurulent secretions, and } \\
\text { inflamed mucosa) }\end{array}$ & \\
\hline $\begin{array}{l}\text { Systemic medication needed to } \\
\text { control disease }\end{array}$ & Not needed & $\begin{array}{l}\text { Need of a course of antibiotics or } \\
\text { systemic corticosteroids in the last } \\
3 \text { months }\end{array}$ & $\begin{array}{l}\text { Need of long-term antibiotics or } \\
\text { systemic corticosteroids in the last } \\
\text { month }\end{array}$ \\
\hline
\end{tabular}

Assessment of current clinical control of CRS (in the last month); ${ }^{(1)}$ Fokkens WJ, et al. Rhinol Suppl 2012; 23:3: 1-299; ${ }^{2}$ Present/bothersome: VAS > 5.

Table E2. The lower detection limits for Bio-plex chip assay.

\begin{tabular}{|c|c|}
\hline Target & Lower detection limit \\
\hline IL-1 $\beta$ & $3.2 \mathrm{pg} / \mathrm{ml}$ \\
\hline IL-1Ra & $81.1 \mathrm{pg} / \mathrm{ml}$ \\
\hline IL-2 & $0.5 \mathrm{pg} / \mathrm{ml}$ \\
\hline IL-4 & $2.2 \mathrm{pg} / \mathrm{ml}$ \\
\hline IL-5 & $3.1 \mathrm{pg} / \mathrm{ml}$ \\
\hline IL-6 & $2.3 \mathrm{pg} / \mathrm{ml}$ \\
\hline IL-7 & $3.1 \mathrm{pg} / \mathrm{ml}$ \\
\hline IL-8 & $1.9 \mathrm{pg} / \mathrm{ml}$ \\
\hline IL-9 & $2.1 \mathrm{pg} / \mathrm{ml}$ \\
\hline IL-10 & $2.2 \mathrm{pg} / \mathrm{ml}$ \\
\hline IL-12 & $3.3 \mathrm{pg} / \mathrm{ml}$ \\
\hline IL-13 & $3.7 \mathrm{pg} / \mathrm{ml}$ \\
\hline IL-15 & $2.1 \mathrm{pg} / \mathrm{ml}$ \\
\hline IL-17A & $4.9 \mathrm{pg} / \mathrm{ml}$ \\
\hline IL-22 & $3.88 \mathrm{pg} / \mathrm{ml}$ \\
\hline IL-25 & $1.0 \mathrm{pg} / \mathrm{ml}$ \\
\hline IL-33 & $4.18 \mathrm{pg} / \mathrm{ml}$ \\
\hline Eotaxin & $40.9 \mathrm{pg} / \mathrm{ml}$ \\
\hline bFGF & $27.2 \mathrm{pg} / \mathrm{ml}$ \\
\hline G-CSF & $2.4 \mathrm{pg} / \mathrm{ml}$ \\
\hline
\end{tabular}

\begin{tabular}{|c|c|}
\hline Target & Lower detection limit \\
\hline GM-CSF & $63.3 \mathrm{pg} / \mathrm{ml}$ \\
\hline IFN- $\gamma$ & $92.6 \mathrm{pg} / \mathrm{ml}$ \\
\hline IP10 & $18.8 \mathrm{pg} / \mathrm{ml}$ \\
\hline MCP-1 & $2.1 \mathrm{pg} / \mathrm{ml}$ \\
\hline MIP-1a & $1.4 \mathrm{pg} / \mathrm{ml}$ \\
\hline PDGF-BB & $7.0 \mathrm{pg} / \mathrm{ml}$ \\
\hline MIP-1 $\beta$ & $2.0 \mathrm{pg} / \mathrm{ml}$ \\
\hline RANTES & $2.2 \mathrm{pg} / \mathrm{ml}$ \\
\hline TNF- $a$ & $5.8 \mathrm{pg} / \mathrm{ml}$ \\
\hline VEGF & $5.5 \mathrm{pg} / \mathrm{ml}$ \\
\hline $\operatorname{lgG} 1$ & $0.13 \mathrm{pg} / \mathrm{ml}$ \\
\hline $\operatorname{lgG} 2$ & $2.74 \mathrm{pg} / \mathrm{ml}$ \\
\hline $\operatorname{lgG3}$ & $0.07 \mathrm{pg} / \mathrm{ml}$ \\
\hline $\operatorname{lgG} 4$ & $0.02 \mathrm{pg} / \mathrm{ml}$ \\
\hline $\lg M$ & $0.78 \mathrm{pg} / \mathrm{ml}$ \\
\hline $\lg \mathrm{E}$ & $0.02 \mathrm{pg} / \mathrm{ml}$ \\
\hline $\lg A$ & $0.13 \mathrm{pg} / \mathrm{ml}$ \\
\hline TSLP & $3.0 \mathrm{pg} / \mathrm{ml}$ \\
\hline CCL17 & $1.7 \mathrm{pg} / \mathrm{ml}$ \\
\hline
\end{tabular}

IL, interleukin; IL-1Ra, IL-1 receptor antagonist; bFGF, basic fibroblast growth factor; G-CSF, granulocyte colony-stimulating factor; GM-CSF, granulocyte-macrophage colony-stimulating factor; IFN- $\gamma$, interferon- $\gamma$; IP-10, IFN- $\gamma$-induced protein 10; MCP, monocyte chemoattractant protein; MIP, macrophage inflammatory protein; PDGF-BB, platelet-derived growth factor-BB; RANTES, regulated upon activation normal T cell expressed and secreted; TNF, tumor necrosis factor; VEGF, vascular endothelial growth factor; Ig, immunoglobulin; TSLP, thymic stromal lymphopoietin; CCL, chemokine (C-C motif) ligand. 
Table E3. Baseline characteristics of patients finally analyzed and patients with inadequate sample amount or lost to follow-up in the cohort with nasal secretion sample.

\begin{tabular}{|c|c|c|c|}
\hline & $\begin{array}{l}\text { Patients with inadequate sample } \\
\text { amount or lost to follow-up } \\
\qquad(n=40)\end{array}$ & $\begin{array}{l}\text { Patients finally analyzed } \\
\qquad(n=189)\end{array}$ & P value \\
\hline Gender, male (\%) & $25(62.50)$ & $119(62.96)$ & 1.000 \\
\hline Age (y) & $37.0(21.0-48.0)$ & $42.0(28.0-50.0)$ & 0.115 \\
\hline Atopy, n (\%) & $14(35.00)$ & $77(40.74)$ & 0.595 \\
\hline$A R, n(\%)$ & $6(15.00)$ & $33(17.46)$ & 0.820 \\
\hline Asthma, n (\%) & $2(5.00)$ & $15(7.94)$ & 0.744 \\
\hline Prior surgery, n (\%) & $10(25.00)$ & $52(27.51)$ & 0.846 \\
\hline Nasal polyps, n (\%) & $26(65.0)$ & $133(70.37)$ & 0.571 \\
\hline Disease duration (y) & $3.0(2.0-10.0)$ & $4.0(1.0-10.0)$ & 0.653 \\
\hline Nasal obstruction VAS score & $8.0(5.0-8.0)$ & $7.0(5.0-9.0)$ & 0.741 \\
\hline Rhinorrhea VAS score & $6.0(5.0-8.0)$ & $5.0(3.0-7.0)$ & 0.573 \\
\hline Headache VAS score & $2.0(0-6.0)$ & $3.0(0-6.0)$ & 0.573 \\
\hline Facial pain VAS score & $0(0-3.0)$ & $0(0-3.0)$ & 0.756 \\
\hline Loss of smell VAS score & $4.0(1.0-8.0)$ & $5.0(2.0-9.0)$ & 0.148 \\
\hline Total symptom VAS score & $20.0(15.0-27.0)$ & $21.0(15.0-29.0)$ & 0.924 \\
\hline Overall burden VAS score & $7.0(5.0-8.0)$ & $6.0(4.0-8.0)$ & 0.333 \\
\hline Nasal polyp score & $2.0(0-4.0)$ & $2.0(0-4.0)$ & 0.211 \\
\hline Bilateral CT score & $15.0(11.0-19.0)$ & $13.0(7.0-19.0)$ & 0.133 \\
\hline Total endoscopic score & $7.0(4.0-8.0)$ & $8.0(5.0-10.0)$ & 0.302 \\
\hline Blood leukocyte count (×109/L) & $6.39(4.98-7.78)$ & $5.86(5.04-7.03)$ & 0.303 \\
\hline Blood neutrophil count $\left(\times 10^{9} / \mathrm{L}\right)$ & $3.40(2.69-4.23)$ & $3.00(2.47-3.81)$ & 0.196 \\
\hline Blood neutrophil ratio (\%) & $54.45(49.28-59.60)$ & $52.25(46.80-57.60)$ & 0.125 \\
\hline Blood lymphocyte count $\left(\times 10^{9} / \mathrm{L}\right)$ & $1.97(1.66-2.26)$ & $2.05(1.65-2.46)$ & 0.562 \\
\hline Blood lymphocyte ratio (\%) & $33.40(28.40-38.73)$ & $34.50(29.20-40.93)$ & 0.271 \\
\hline Blood eosinophil count $\left(\times 10^{9} / \mathrm{L}\right)$ & $0.17(0.08-0.27)$ & $0.18(0.12-0.37)$ & 0.228 \\
\hline Blood eosinophil ratio (\%) & $2.87(1.78-5.13)$ & $3.10(1.90-5.50)$ & 0.189 \\
\hline Blood monocyte count ( $\left.\times 10^{9} / \mathrm{L}\right)$ & $0.48(0.36-0.70)$ & $0.43(0.35-0.55)$ & 0.136 \\
\hline Blood monocyte ratio (\%) & $7.30(5.58-9.13)$ & $7.20(6.30-8.70)$ & 0.681 \\
\hline
\end{tabular}

Data are presented as medians (inter-quartile ranges) or $n$ (\%). Bold indicates statistical significance $(P<0.05)$. CRS, chronic rhinosinusitis; AR, allergic rhinitis; VAS, visual analog scale; CT, computed tomography.

Table E4. Baseline characteristics of patients finally analyzed and patients with inadequate sample amount or lost to follow-up in the cohort with blood sample.

\begin{tabular}{|c|c|c|c|}
\hline & $\begin{array}{l}\text { Patients with inadequate sample } \\
\text { amount or lost to follow-up } \\
\text { ( } n=18)\end{array}$ & $\begin{array}{l}\text { Patients finally analyzed } \\
\qquad(n=128)\end{array}$ & $P$ value \\
\hline Gender, male (\%) & $10(55.56)$ & $78(60.94)$ & 0.798 \\
\hline Age (y) & $44.00(22.00-55.00)$ & $43.50(29.00-52.00)$ & 0.990 \\
\hline Atopy, n (\%) & $4(22.22)$ & $50(39.00)$ & 0.200 \\
\hline$A R, n(\%)$ & $3(16.67)$ & $25(19.53)$ & 1.000 \\
\hline Asthma, n (\%) & $2(11.11)$ & $12(9.37)$ & 0.685 \\
\hline Prior surgery, $\mathrm{n}(\%)$ & $5(27.78)$ & $28(21.88)$ & 0.557 \\
\hline Nasal polyps, n (\%) & $13(72.22)$ & 91 (71.09) & 1.000 \\
\hline Disease duration (y) & $5.0(1.0-9.0)$ & $3.0(1.0-10.0)$ & 0.928 \\
\hline
\end{tabular}




\begin{tabular}{|c|c|c|c|}
\hline & $\begin{array}{l}\text { Patients with inadequate sample } \\
\text { amount or lost to follow-up } \\
\qquad(n=18)\end{array}$ & $\begin{array}{l}\text { Patients finally analyzed } \\
\qquad(n=128)\end{array}$ & P value \\
\hline Nasal obstruction VAS score & $6.0(5.0-9.0)$ & $7.0(5.0-8.0)$ & 0.794 \\
\hline Rhinorrhea VAS score & $6.0(3.0-8.0)$ & $5.0(3.0-7.0)$ & 0.420 \\
\hline Headache VAS score & $2.0(1.0-5.0)$ & $3.0(0-5.0)$ & 0.937 \\
\hline Facial pain VAS score & $0(0-3.0)$ & $0(0-4.0)$ & 0.426 \\
\hline Loss of smell VAS score & $5.0(1.0-9.0)$ & $5.0(2.0-8.0)$ & 0.707 \\
\hline Total symptom VAS score & $25.0(12.0-27.0)$ & $20.0(16.0-26.0)$ & 0.851 \\
\hline Overall burden VAS score & $6.0(4.0-8.0)$ & $6.0(5.0-8.0)$ & 0.916 \\
\hline Nasal polyp score & $2.0(0-4.0)$ & $2.0(0-4.0)$ & 0.897 \\
\hline Bilateral CT score & $14.0(8.0-20.0)$ & $14.0(8.0-20.0)$ & 0.761 \\
\hline Total endoscopic score & $6.0(4.0-9.0)$ & $8.0(5.0-9.0)$ & 0.316 \\
\hline Blood leukocyte count (×109/L) & $6.16(5.18-6.92)$ & $5.97(4.95-7.04)$ & 0.897 \\
\hline Blood neutrophil count $\left(\times 10^{9} / \mathrm{L}\right)$ & $3.00(2.54-3.47)$ & $3.21(2.35-3.92)$ & 0.753 \\
\hline Blood neutrophil ratio (\%) & $51.85(44.40-57.80)$ & $52.80(45.60-58.35)$ & 0.733 \\
\hline Blood lymphocyte count $\left(\times 10^{9} / \mathrm{L}\right)$ & $1.92(1.66-2.35)$ & $1.95(1.66-2.44)$ & 0.967 \\
\hline Blood lymphocyte ratio (\%) & $36.90(30.70-39.45)$ & $34.50(29.25-39.30)$ & 0.307 \\
\hline Blood eosinophil count $\left(\times 10^{9} / \mathrm{L}\right)$ & $0.22(0.15-0.34)$ & $0.22(0.11-0.43)$ & 0.820 \\
\hline Blood eosinophil ratio (\%) & $3.50(2.28-5.25)$ & $3.20(1.75-6.55)$ & 0.797 \\
\hline Blood monocyte count $\left(\times 10^{9} / \mathrm{L}\right)$ & $0.49(0.37-0.58)$ & $0.44(0.35-0.57)$ & 0.441 \\
\hline Blood monocyte ratio (\%) & $8.10(5.55-9.28)$ & $7.40(6.25-8.85)$ & 0.604 \\
\hline
\end{tabular}

Data are presented as medians (inter-quartile ranges) or $n(\%)$. Bold indicates statistical significance $(P<0.05)$. CRS, chronic rhinosinusitis; AR, allergic rhinitis; VAS, visual analog scale; CT, computed tomography.

Table E5. Baseline characteristics of finally analyzed patients in the cohort with nasal secretion sample and cohort with blood sample.

\begin{tabular}{|c|c|c|c|}
\hline & $\begin{array}{l}\text { Patients with nasal secretion } \\
\text { sample } \\
\text { ( } n=189)\end{array}$ & $\begin{array}{l}\text { Patients with blood sample } \\
\qquad(n=128)\end{array}$ & P value \\
\hline Gender, male (\%) & $119(62.96)$ & $78(60.94)$ & 0.728 \\
\hline Age (y) & $42.0(28.0-50.0)$ & $43.50(29.00-52.00)$ & 0.220 \\
\hline Atopy, n (\%) & $77(40.74)$ & $50(39.00)$ & 0.816 \\
\hline$A R, n(\%)$ & $33(17.46)$ & $25(19.53)$ & 0.659 \\
\hline Asthma, n (\%) & $15(7.94)$ & $12(9.37)$ & 0.685 \\
\hline Prior surgery, n (\%) & $52(27.51)$ & $28(21.88)$ & 0.293 \\
\hline Nasal polyps, n (\%) & $133(70.37)$ & 91 (71.09) & 0.910 \\
\hline Disease duration (y) & $4.0(1.0-10.0)$ & $3.0(1.0-10.0)$ & 0.187 \\
\hline Nasal obstruction VAS score & $7.0(5.0-9.0)$ & $7.0(5.0-8.0)$ & 0.171 \\
\hline Rhinorrhea VAS score & $5.0(3.0-7.0)$ & $5.0(3.0-7.0)$ & 0.689 \\
\hline Headache VAS score & $3.0(0-6.0)$ & $3.0(0-5.0)$ & 0.483 \\
\hline Facial pain VAS score & $0(0-3.0)$ & $0(0-4.0)$ & 0.324 \\
\hline Loss of smell VAS score & $5.0(2.0-9.0)$ & $5.0(2.0-8.0)$ & 0.434 \\
\hline Total symptom VAS score & $21.0(15.0-29.0)$ & $20.0(16.0-26.0)$ & 0.602 \\
\hline Overall burden VAS score & $6.0(4.0-8.0)$ & $6.0(5.0-8.0)$ & 0.705 \\
\hline Nasal polyp score & $2.0(0-4.0)$ & $2.0(0-4.0)$ & 0.526 \\
\hline Bilateral CT score & $13.0(7.0-19.0)$ & $14.0(8.0-20.0)$ & 0.481 \\
\hline Total endoscopic score & $8.0(5.0-10.0)$ & $8.0(5.0-9.0)$ & 0.924 \\
\hline Blood leukocyte count (×109/L) & $5.86(5.04-7.03)$ & $5.97(4.95-7.04)$ & 0.930 \\
\hline
\end{tabular}




\begin{tabular}{|c|c|c|c|}
\hline & $\begin{array}{l}\text { Patients with nasal secretion } \\
\text { sample } \\
\text { ( } n=189)\end{array}$ & $\begin{array}{l}\text { Patients with blood sample } \\
\qquad(n=128)\end{array}$ & P value \\
\hline Blood neutrophil count $\left(\times 10^{9} / \mathrm{L}\right)$ & $3.00(2.47-3.81)$ & $3.21(2.35-3.92)$ & 0.954 \\
\hline Blood neutrophil ratio (\%) & $52.25(46.80-57.60)$ & $52.80(45.60-58.35)$ & 0.986 \\
\hline Blood lymphocyte count (×109/L) & $2.05(1.65-2.46)$ & $1.95(1.66-2.44)$ & 0.667 \\
\hline Blood lymphocyte ratio (\%) & $34.50(29.20-40.93)$ & $34.50(29.25-39.30)$ & 0.592 \\
\hline Blood eosinophil count $\left(\times 10^{9} / \mathrm{L}\right)$ & $0.18(0.12-0.37)$ & $0.22(0.11-0.43)$ & 0.548 \\
\hline Blood eosinophil ratio (\%) & $3.10(1.90-5.50)$ & $3.20(1.75-6.55)$ & 0.822 \\
\hline Blood monocyte count $\left(\times 10^{9} / \mathrm{L}\right)$ & $0.43(0.35-0.55)$ & $0.44(0.35-0.57)$ & 0.648 \\
\hline Blood monocyte ratio (\%) & $7.20(6.30-8.70)$ & $7.40(6.25-8.85)$ & 0.704 \\
\hline
\end{tabular}

Data are presented as medians (inter-quartile ranges) or $n$ (\%). Bold indicates statistical significance $(P<0.05)$. CRS, chronic rhinosinusitis; AR, allergic rhinitis; VAS, visual analog scale; CT, computed tomography.

Table E6. Baseline characteristics of the cohort with blood sample.

\begin{tabular}{|c|c|c|c|}
\hline & $\begin{array}{l}\text { Non-difficult-to-treat CRS } \\
\qquad(n=97)\end{array}$ & $\begin{array}{l}\text { Difficult-to-treat CRS } \\
\qquad(n=31)\end{array}$ & P value \\
\hline Gender, male (\%) & $59(60.82)$ & 19 (61.29) & 1.000 \\
\hline Age (y) & $44.0(29.0-53.0)$ & $43.0(30.0-52.0)$ & 0.909 \\
\hline Atopy, n (\%) & $33(34.00)$ & $17(54.80)$ & 0.037 \\
\hline$A R, n(\%)$ & $13(14.43)$ & $12(38.70)$ & 0.004 \\
\hline Asthma, n (\%) & $3(3.10)$ & $9(29.03)$ & $<0.001$ \\
\hline Prior surgery, n (\%) & $16(16.45)$ & $12(38.71)$ & 0.011 \\
\hline Nasal polyps, n (\%) & $63(64.95)$ & $28(90.32)$ & 0.006 \\
\hline Disease duration (y) & $3.5(1.0-8.0)$ & $5.0(2.0-10.0)$ & 0.173 \\
\hline Nasal obstruction VAS score & $6.0(4.0-8.0)$ & $7.0(6.0-8.0)$ & 0.046 \\
\hline Rhinorrhea VAS score & $5.0(3.0-7.0)$ & $5.0(3.0-7.0)$ & 0.682 \\
\hline Headache VAS score & $3.0(0-6.0)$ & $4.0(0-5.0)$ & 0.546 \\
\hline Facial pain VAS score & $0(0-4.0)$ & $1.0(0-3.0)$ & 0.806 \\
\hline Loss of smell VAS score & $4.0(1.0-8.0)$ & $8.0(4.0-10.0)$ & 0.002 \\
\hline Total symptom VAS score & $20.0(15.0-26.0)$ & $25.0(19.0-29.0)$ & 0.014 \\
\hline Overall burden VAS score & $6.0(5.0-7.0)$ & $6.0(5.0-8.0)$ & 0.592 \\
\hline Nasal polyp score & $2.0(0-4.0)$ & $4.0(2.0-4.0)$ & $<0.001$ \\
\hline Bilateral CT score & $11.0(5.0-7.0)$ & $21.0(17.0-24.0)$ & $<0.001$ \\
\hline Ethmoid sinus score & $4.0(2.0-7.0)$ & $7.0(6.0-8.0)$ & $<0.001$ \\
\hline Maxillary sinus score & $2.0(2.0-4.0)$ & $4.0(2.0-4.0)$ & 0.010 \\
\hline E/M ratio & $1.67(1.30-2.2)$ & $1.8(1.8-2.13)$ & 0.205 \\
\hline $\mathrm{PE} / \mathrm{AE}$ ratio & $1.00(1.00-1.25)$ & $1.00(1.00-1.20)$ & 0.105 \\
\hline Total endoscopic score & $6.0(4.0-8.0)$ & $8.0(6.0-10.0)$ & 0.012 \\
\hline Blood leukocyte count (×109/L) & $6.19(4.86-6.60)$ & $6.40(5.12-7.17)$ & 0.174 \\
\hline Blood neutrophil count $\left(\times 10^{9} / \mathrm{L}\right)$ & $2.91(2.29-3.77)$ & $3.35(2.39-3.94)$ & 0.157 \\
\hline Blood neutrophil ratio (\%) & $52.90(45.50-57.80)$ & $51.50(45.25-56.13)$ & 0.777 \\
\hline Blood lymphocyte count $\left(\times 10^{9} / \mathrm{L}\right)$ & $1.92(1.62-3.89)$ & $1.99(1.67-2.51)$ & 0.432 \\
\hline Blood lymphocyte ratio (\%) & $35.35(29.38-40.30)$ & $31.50(29.88-36.10)$ & 0.121 \\
\hline Blood eosinophil count $\left(\times 10^{9} / L\right)$ & $0.17(0.10-0.33)$ & $0.37(0.17-0.61)$ & 0.006 \\
\hline Blood eosinophil ratio (\%) & $2.65(1.60-4.75)$ & $4.70(3.10-9.35)$ & 0.007 \\
\hline Blood monocyte count $\left(\times 10^{9} / \mathrm{L}\right)$ & $0.42(0.35-0.55)$ & $0.49(0.34-0.60)$ & 0.171 \\
\hline
\end{tabular}




\begin{tabular}{|c|c|c|c|}
\hline & $\begin{array}{l}\text { Non-difficult-to-treat CRS } \\
\qquad(n=97)\end{array}$ & $\begin{array}{l}\text { Difficult-to-treat CRS } \\
\qquad(\mathbf{n}=\mathbf{3 1})\end{array}$ & P value \\
\hline Blood monocyte ratio (\%) & $7.50(6.28-8.90)$ & $7.30(6.20-8.68)$ & 0.699 \\
\hline
\end{tabular}

Data are presented as medians (inter-quartile ranges) or $n(\%)$. Bold indicates statistical significance $(P<0.05)$. CRS, chronic rhinosinusitis; $A R$, allergic rhinitis; VAS, visual analog scale; $C T$, computed tomography; $E$, ethmoid sinus score; $M$, maxillary sinus score; $A E$, anterior ethmoid score; $P E$, posterior ethmoid score.

Table E7. Plasma biomarkers in patients with and without difficult-to-treat CRS.

\begin{tabular}{|c|c|c|c|}
\hline & $\begin{array}{l}\text { Non-difficult-to-treat CRS } \\
\qquad(n=97)\end{array}$ & $\begin{array}{l}\text { Difficult-to-treat CRS } \\
\qquad(n=31)\end{array}$ & P value \\
\hline $\mathrm{IL}-1 \beta(\mathrm{pg} / \mathrm{ml})$ & $2.01(1.67-2.57)$ & $2.08(1.78-2.51)$ & 0.376 \\
\hline IL-1Ra (pg/ml) & $53.4(40.00-67.96)$ & $53.80(43.90-73.37)$ & 0.496 \\
\hline IL-2 (pg/ml) & $17.51(12.59-27.54)$ & $17.65(12.45-28.87)$ & 0.699 \\
\hline IL-4 (pg/ml) & $2.68(2.38-3.04)$ & $2.95(2.36-3.27)$ & 0.367 \\
\hline IL-5 (pg/ml) & $6.56(6.10-7.43)$ & $7.39(6.13-8.7)$ & 0.139 \\
\hline IL-6 (pg/ml) & $6.89(5.74-8.96)$ & $7.27(6.51-9.75)$ & 0.402 \\
\hline IL-7 (pg/ml) & $2.56(1.44-4.53)$ & $3.44(1.95-7.83)$ & 0.090 \\
\hline IL-8 (pg/ml) & $12.61(9.95-16.86)$ & $13.34(10.74-17.75)$ & 0.375 \\
\hline IL-9 (pg/ml) & $34.10(26.44-40.54)$ & $34.06(28.76-38.55)$ & 0.953 \\
\hline IL-10 (pg/ml) & $6.20(4.76-8.99)$ & $7.62(5.50-9.98)$ & 0.339 \\
\hline IL-12 (pg/ml) & $6.04(3.52-11.84)$ & $6.84(5.21-13.14)$ & 0.139 \\
\hline IL-13 (pg/ml) & $1.58(0.89-3.63)$ & $2.05(1.41-4.31)$ & 0.261 \\
\hline IL-15 (pg/ml) & $6.30(4.68-13.68)$ & $6.34(5.62-12.25)$ & 0.306 \\
\hline IL-17A (pg/ml) & $35.50(27.87-45.23)$ & $36.51(29.60-49.66)$ & 0.279 \\
\hline IL-22 (pg/ml) & $179.00(160.98-196.82)$ & $196.82(167.01-208.59)$ & 0.146 \\
\hline IL-25 (pg/ml) & $17.22(15.87-18.57)$ & $16.77(16.12-18.12)$ & 0.757 \\
\hline Eotaxin (pg/ml) & $73.62(52.67-102.22)$ & $65.91(55.83-86.13)$ & 0.730 \\
\hline bFGF (pg/ml) & $18.44(16.32-20.46)$ & $18.26(16.00-20.97)$ & 0.724 \\
\hline IP-10 (ng/ml) & $0.78(0.56-1.01)$ & $0.71(0.49-1.20)$ & 0.697 \\
\hline MCP-1 (pg/ml) & $49.52(43.94-62.59)$ & $53.59(46.75-73.89)$ & 0.161 \\
\hline MIP-1a (pg/ml) & $2.67(2.16-3.23)$ & $2.90(2.44-3.35)$ & 0.076 \\
\hline PDGF-BB (pg/ml) & $2.36(1.70-3.41)$ & $2.80(1.50-3.85)$ & 0.483 \\
\hline MIP-1 $\beta(p g / m l)$ & $96.83(61.21-123.77)$ & $106.63(90.78-121.60)$ & 0.096 \\
\hline RANTES (pg/ml) & $8.39(7.43-10.86)$ & $8.52(5.92-11.63)$ & 0.526 \\
\hline TNF-a (pg/ml) & $27.84(25.18-32.88)$ & $29.27(27.47-33.60)$ & 0.136 \\
\hline $\operatorname{VEGF}(\mathrm{pg} / \mathrm{ml})$ & $25.76(10.62-62.26)$ & $34.81(18.18-64.81)$ & 0.198 \\
\hline $\operatorname{lgG} 1(\mathrm{ng} / \mathrm{ml})$ & $5.24(3.92-7.57)$ & $5.17(3.67-7.64)$ & 0.982 \\
\hline $\operatorname{lgG} 2(\mathrm{ng} / \mathrm{ml})$ & $4.04(2.92-5.78)$ & $4.44(3.59-5.51)$ & 0.258 \\
\hline $\operatorname{lgG} 3(\mathrm{ng} / \mathrm{ml})$ & $0.40(0.24-0.61)$ & $0.39(0.23-0.63)$ & 0.931 \\
\hline lgG4 (ng/ml) & $0.33(0.17-0.63)$ & $0.49(0.20-0.64)$ & 0.188 \\
\hline $\lg A(n g / m l)$ & $1.02(0.80-1.55)$ & $1.10(0.78-1.41)$ & 0.745 \\
\hline $\operatorname{lgM}(\mathrm{ng} / \mathrm{ml})$ & $1.14(0.80-1.56)$ & $1.26(0.96-1.67)$ & 0.294 \\
\hline $\lg E(p g / m l)$ & $138.46(47.04-431.04)$ & $168.7(59.17-507.52)$ & 0.372 \\
\hline $\mathrm{CCL} 17$ (pg/ml) & $103.12(34.26-212.08)$ & $72.41(22.05-173.55)$ & 0.549 \\
\hline TSLP (pg/ml) & $3.47(1.38-6.89)$ & $3.79(2.70-8.88)$ & 0.316 \\
\hline
\end{tabular}

Data are presented as medians (inter-quartile ranges). Bold indicates statistical significance $(\mathrm{P}<0.05)$. IL, interleukin; IL-1 Ra, IL-1 receptor antagonist; bFGF, basic fibroblast growth factor; MCP-1, monocyte chemoattractant protein-1; MIP, macrophage inflammatory protein; TNF- $a$, tumor necrosis factor $a$; VEGF, vascular endothelial growth factor; PDGF-BB, platelet-derived growth factor-BB; Ig, immunoglobulin; TSLP, thymic stromal lymphopoietin; $\mathrm{CCL}$, chemokine (C-C motif) ligand; RANTES, regulated on activation, normal T-cell expressed and secreted. 